\title{
Core-Shell Microcapsules from Unpurified Legume Flours
}

\author{
Xiufeng Li, Jasper van der Gucht, Philipp Erni, and Renko de Vries* \\ Cite This: ACS Appl. Mater. Interfaces 2021, 13, 37598-37608 \\ Read Online
}

ABSTRACT: Plant-based ingredients are key building blocks for future sustainable advanced materials. Functionality is typically higher for highly purified plant-based ingredients, but this is at the expense of their sustainability value. Here, a method is introduced for creating a soft functional material, with structural elements ranging from the nanometer to the millimeter scale, directly from legume flours. Globulins from soy and pea flours are extracted in their native state at acidic $\mathrm{pH}$ and mixed with gum arabic, resulting in liquid-liquid phase separation into a dilute phase and a viscoelastic complex coacervate. Interfacial tensions of the coacervates, determined via AFM-based probing of capillary condensation, are found to be very low $(\gamma=48.5$ and $32.3 \mu \mathrm{N} / \mathrm{m}$ for, respectively, soy and pea $)$, thus promoting the deposition of a shell of coacervate material around oil droplets. Despite the complex nature of the starting material, the dependence of interfacial tensions on salt concentrations follows a scaling law previously shown to hold for model complex coacervates. Curing of the coacervate material into a strong and purely elastic hydrogel is shown to be possible via simple heating, both in bulk and as a shell around oil droplets, thus providing proof of principle for the fabrication of precise core-shell microcapsules directly from legume flours.

KEYWORDS: plant protein, complex coacervation, core-shell capsule, encapsulation, interfacial tension, AFM

\section{INTRODUCTION}

For future sustainable materials, increasing attention is being directed to plants as a source of raw starting material. ${ }^{1-4}$ Either these can be converted into biobased chemicals via microbial fermentation, such as fuel from biomass conversion, ${ }^{5,6}$ or one can try to directly utilize polymers from plants to fabricate plant-based materials for medical applications, functional coatings, drug delivery, food, and nutrition. ${ }^{7-9}$ One of the challenges with the latter approach is the complexity of plantbased ingredients. For clear structure-property relations and rational material design, one would expect that it would be the best to work with purified plant polymers, but extracting pure polymers from raw plant-based ingredients is both complex and costly. ${ }^{10}$ Additionally, and may be even more importantly, such purification efforts use only part of the plant materials and often require substantial water and energy. Hence, they are at odds with the sustainability value of plant-based materials. Therefore, there is an urgent need for more sustainable methods to extract the target ingredients from plants ${ }^{11}$ or easier ways to create well-defined functional materials starting directly from raw plant materials. ${ }^{12,13}$

A case in point is core-shell microcapsules, which consist of a polymer shell with a cargo encapsulated as the core. They have a wide range of applications in pharma, food, and personal care. ${ }^{14-16}$ One of the approaches to fabricate coreshell microcapsules is via coacervation: liquid-liquid phase separation in polymer solutions where one of the phases is highly concentrated in the polymer and the other phase is extremely dilute in the polymer. The concentrated coacervate phase typically still contains a significant fraction of solvent and hence has a very low interfacial tension with the excess phase. As a consequence, coacervates typically wet a wide range of materials. By slowly moving from the one-phase region into the two-phase region, it is possible to deposit a coacervate shell around, for example, oil droplets. Core-shell capsules are created by subsequently curing such coacervate liquid shells into an elastic material. ${ }^{17}$

A specific case of coacervation is complex coacervation, where electrostatic attraction between oppositely charged polymers drives coacervation. These phenomena were first systematically studied by De Jong and Bungenberg in $1932^{18}$ and have since then been investigated for many types of mixtures of oppositely charged water-soluble macromolecules, such as proteins, colloids, and polysaccharides. ${ }^{19}$ As for coacervates in general, complex coacervates have a high polymer content (typically between 10 and $40 \% \mathrm{w} / \mathrm{w}$ ) while remaining liquid. They have very low interfacial tensions with their excess phases (of order $100 \mu \mathrm{N} / \mathrm{m}$ ). ${ }^{20}$ These features make complex coacervates appealing not only to fabricate core-shell capsules for drugs, nutrients, and flavors, ${ }^{21}$ but also, for example, as underwater adhesives and coatings. ${ }^{22}$

For many applications of core-shell microcapsules, naturally sourced polymers (proteins and polysaccharides) are preferred

Received: April 14, 2021

Accepted: July 20, 2021

Published: July 30, 2021 
if they can provide the same functionalities as their counterparts from synthetic routes. ${ }^{23}$ However, often, the latter is not the case. Nevertheless, gelatin has been widely used at an industrial scale for core-shell microcapsules fabricated via complex coacervation. ${ }^{17}$ For reasons of sustainability and consumer preference, many researchers are now attempting to use just plant-based proteins and polysaccharides for fabricating core-shell microcapsules via complex coacervation. Indeed, several plant proteins, such as soy, pea, canola, and flaxseed proteins, show the potential to form complex coacervates with a variety of polysaccharides, for instance, gum arabic, alginate, chitosan, and pectin. ${ }^{24,25}$ However, using plant proteins to formulate complex coacervates at a large scale, for use in industrial applications, is still challenging. ${ }^{9}$ Challenges include the often rather poor solubility of commercial protein isolates from major plant protein sources, such as leguminous plants, and their low functionality, which is at least in part due to current plant protein purification methods, that lead to a large degree of protein denaturation and aggregation. Hence, they are often difficult to dissolve down to the single protein level, which is essential for obtaining homogeneous complex coacervates rather than coprecipitates.

In a recent study, ${ }^{10}$ Tanger et al. compared three commonly used extraction methods for pea proteins: alkali extraction followed by isoelectric precipitation, micellar precipitation, and salt extraction followed by dialysis. They show that both solubilization and precipitation steps have an impact on the protein conformation. Proteins are denatured in the solubilization step, while irreversible and reversible aggregation occurs at the precipitation step. Alkali extraction with isoelectric precipitation is the most efficient and common method in industry. ${ }^{26}$ However, the isoelectric precipitation causes most irreversible aggregates, as also reported elsewhere. ${ }^{27}$ The other two methods use the salting-in effect, which dissolves proteins under high salt conditions. For micellar precipitation, the solution with high salt concentration is quickly diluted in cold water, and proteins tend to form micelles and precipitates. These proteins can be resolubilized at a high salt concentration, which is not favorable for complex coacervation. The last one is the mildest method among the three, but the dialysis step takes much longer time and costs more, which make this method often only used in laboratories but less preferred in industry. Not surprisingly, therefore, many studies on complex coacervation of plant proteins and polysaccharides have been performed not with industrially available protein isolates but rather with plant proteins purified to a high degree using more gentle laboratory-scale methods. ${ }^{28-30}$ Since many of these studies have been motivated by practical/technical/ medical applications, so scalability is an important aspect, which our work presented here addresses.

Understanding the effect of compositional parameters, extraction pathways, and physicochemical interactions on the structural and mechanical characteristics of the resulting coacervates is a key for the rational design of coacervate capsules that are suitable as delivery systems in the applications outlined above. The main innovation we present here, to allow for core-shell capsule formation directly from legume flours, is to use acid extraction of the proteins from the legume flour rather than alkali extraction. The latter inevitably leads to protein denaturation that is incompatible with the formation of homogeneous complex coacervates. In the acidic environment, the plant proteins can directly form complex coacervates with weakly anionic polymers, such as gum arabic. ${ }^{31}$ Globulins, the main fraction from leguminous seed proteins, carry positive net charges below their isoelectric points (mostly below 5), and most polysaccharides are anionic polymers in a wide $\mathrm{pH}$ range. Thus, the narrow window for their complex coacervation is typically located at low $\mathrm{pH}$. Furthermore, by never exposing the proteins to $\mathrm{pH}$ close to their isoelectric point (around $\mathrm{pH}$ 5 ), they retain their native and soluble state suitable for making homogeneous complex coacervates. In view of their extremely low interfacial tensions, quantitation of the interfacial behavior of complex coacervates, which is crucial for their application in core-shell microcapsule fabrication, is challenging. Previously, it has been shown that colloidal probe atomic force microscopy (CP-AFM) allows for a detailed analysis of the capillary condensation of model coacervates. This capillary condensation occurs in the nanoscale gap between colloids and a nearby macroscopically flat surface..$^{20,32-34}$ Surprisingly, we find that the CP-AFM technique works equally well for the highly impure mixtures that we use here. As methodological innovation, we show that dissipation due to coacervate viscosity makes a non-negligible contribution to the force at finite retraction speeds, and we show how to correct for this effect to obtain more accurate determinations of the coacervate interfacial tensions.

\section{RESULTS AND DISCUSSION}

We choose two industrial legume crops, soy and pea, as representative plant protein sources to show suitability of the processing methodology for the variability coming with different protein sources. First, we show that neither commercial pea and soy protein isolates nor proteins alkaliextracted from pea and (defatted) soy flour are suitable for making homogeneous complex coacervates with gum arabic. Next, we analyze in detail the acid extraction of proteins from pea and soy flours, study complex coacervation of the extracted proteins with gum arabic, and study the interfacial properties as well as the mechanical properties of the coacervates (both before and after heating). Finally, we demonstrate core-shell microcapsule formation and the successful heat-induced curing of the shells.

Comparison Study on Complex Formation. While, in principle, one could try to make complex coacervates at either side of the isoelectric point of plant proteins (around $\mathrm{pH} 5$ for the pea and soy proteins that we consider here), in practice, one is limited by the availability of suitable polysaccharides that have opposite signs of the charge (as compared to the proteins) at these $\mathrm{pH}$ values. Quite a few plant polysaccharides are available (such as gum arabic or pectins) that still have a weak negative charge at low $\mathrm{pH}$, say at $\mathrm{pH}$ 3. These are ideal for complex coacervate formation with the pea and soy proteins that are positively charged at low $\mathrm{pH}$. Here, we use gum arabic, which has been very well-characterized with respect to its complex coacervation behavior with proteins at low $\mathrm{pH} .{ }^{19}$ Note that weakly charged rather than highly charged polysaccharides are optimal, since the latter induces solidliquid phase separation (or precipitation) rather than liquidliquid phase separation (or complex coacervation). ${ }^{19,35}$ At higher $\mathrm{pH}$ values, above the isoelectric point of the plant proteins, the proteins are negatively charged. Very few polysaccharides exist that are weakly positively charged at relatively high $\mathrm{pH}$, as required to form complex coacervates with plant proteins, which are negatively charged at $\mathrm{pH}$ values above their isoelectric points. One of the few that is available is 
chitosan, which is a chemically modified version of the natural polysaccharide chitin. However, chitosan is only soluble at $\mathrm{pH}$ values below about $6 .^{36}$ This then leaves a rather narrow window of $\mathrm{pH}$ values, in between the solubility limit of chitosan and the isoelectric point of the plant proteins, where complex coacervates of chitosan and plant proteins may potentially form. For exploring complex coacervation of pea and soy proteins above their isoelectric point, we here use chitosan at $\mathrm{pH}$ 5.8, a $\mathrm{pH}$ in between the pea and soy protein isoelectric point and the solubility limit of the chitosan. In addition, although polysaccharides can still interact with proteins close to the isoelectric point, their weak interactions usually lead to the formation of soluble complexes even if the protein can still exhibit high solubility. ${ }^{37}$ Therefore, the $\mathrm{pH}$ range close to the isoelectric point is not considered in our study.

First, we study the complexation behavior of commercial isolates of pea and soy protein. As shown in Figure S1, the commercial protein isolates are not completely soluble, neither at $\mathrm{pH} 3$ nor at $\mathrm{pH}$ 5.8: the solutions remain turbid. Microscopy images of mixtures of these protein dispersions at $\mathrm{pH} 3$ with gum arabic and mixtures of the protein dispersions at $\mathrm{pH} 5.8$ with chitosan are shown in Figure S2. For both cases, we observe solid precipitates rather than liquid complex coacervates. This may very well be related to the presence of the larger protein aggregates that will have very different complexation behaviors with the polysaccharides as compared to molecularly dispersed proteins.

Next, we compare the complexation with these commercially available protein isolates to proteins directly extracted from soy and pea flours. We again consider the two cases of positively charged proteins at $\mathrm{pH} 3$ and negatively charged proteins at $\mathrm{pH}$ 5.8. First, we use alkali extraction (at $\mathrm{pH}$ 8) of proteins from soy and pea flour, followed by a change in $\mathrm{pH}$ to $\mathrm{pH} 5.8$ to ensure (marginal) solubility of the oppositely charged chitosan. Figure 1A shows a typical example of alkali-extracted

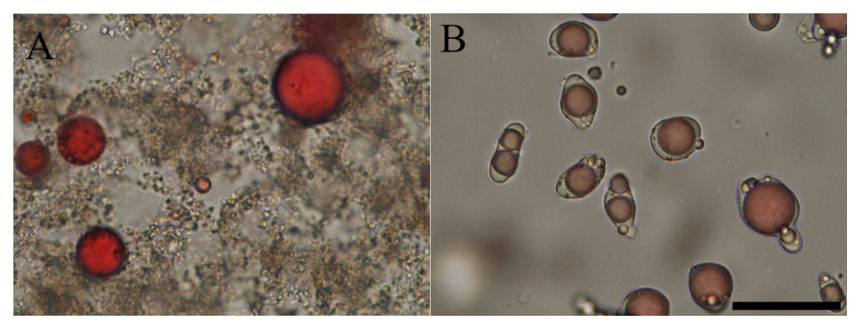

Figure 1. Representative optical microscope images showing the complex formation and interfacial affinity of (A) alkali-extracted pea protein with chitosan at $\mathrm{pH} 5.8$, (B) acid-extracted soy protein with gum arabic at $\mathrm{pH}$ 3. The oil phase was dyed with Oil Red O. The scale bar is $50 \mu \mathrm{m}$.

proteins complexing with chitosan at $\mathrm{pH}$ 5.8: we find the formation of solid precipitates that have little affinity for the water-oil interface. Next, we use acid extraction (at $\mathrm{pH} 3$ ), followed directly by mixing with gum arabic. As shown in Figure 1B, for this case, we find complex coacervates that homogeneously wet the water-oil interface, to form coreshell capsules. The molecular weight and isoelectric point of the same proteins from different sources (commercial, alkaliextracted, and acid-extracted) are expected to be identical or close because they are essentially the same molecules. Here, their distinctive complexation behaviors with oppositely charged polymers were mainly affected by the extraction pathways, which influence the solubility of the proteins at the desired $\mathrm{pH}$ for complex formation.

Extraction Efficiency. Protein extraction efficiency is a key concern for industrial applications; hence, we compare the extraction efficiency of acid extraction at $\mathrm{pH} 3$ with the more typically used alkali extraction. Results are given in Table 1.

Table 1. Protein Yield from Extraction

\begin{tabular}{|c|c|c|c|c|}
\hline type & $\begin{array}{l}\text { protein } \\
\text { content in } \\
\text { flour }[\%]\end{array}$ & $\begin{array}{l}\text { protein } \\
\text { content in } \\
\text { extract [\%] }\end{array}$ & $\begin{array}{l}\text { extracted protein from } \\
\text { total protein content in } \\
\text { flour [\%] }\end{array}$ & $\begin{array}{c}\text { literature } \\
\text { comparison } \\
{[\%]}\end{array}$ \\
\hline Soy & 53.6 & 52.6 & 53.9 & $\begin{array}{l}60-70 \text { (from } \\
\text { alkali } \\
\text { extraction })^{38}\end{array}$ \\
\hline pea & 11.6 & 29.9 & 43.2 & $\begin{array}{l}80 \text { (from } \\
\quad \text { alkali } \\
\text { extraction })^{39}\end{array}$ \\
\hline
\end{tabular}

The protein yield from soy flour and pea flour is 53.9 and $43.2 \%$, respectively. While for soy, this is similar to alkali extraction, protein extraction yields for alkali extraction applied to pea flour can be much higher than this. ${ }^{39}$ The same authors do report for pea flour that similar extraction yields can be obtained for both alkali and acid extraction, if the extraction $\mathrm{pH}$ is lowered down to 1.5 . We here choose not to do so, in order to not loose the advantage of not having to adjust $\mathrm{pH}$, which would amount to an extra process step.

Complex Formation at Different Polymer Ratios. Optimal wetting at the oil-water interface occurs if the coacervate droplets approach electroneutrality (in terms of the charges in the oppositely charged macroions). ${ }^{19,40}$ In view of the complex composition of our protein extracts, it is difficult to predict which composition will be the case. Therefore, we tested a wide range of polymer ratios. For both soy and pea flour extracts, we observe similar behaviors. Microscopy images are shown in Figures 2 and S3. At low gum arabic content, we mainly observe small aggregates. As the ratio of gum arabic to protein extract increases, ever larger coacervate droplets appear until finally, at high gum arabic content, droplets become smaller again.

The precise locations of the optimal ratios at $\mathrm{pH} 3$ were determined more quantitatively by measuring the transmittance of samples (observed after a fixed waiting time) as a function of the gum arabic-to-protein extract ratio. The large complex coacervate droplets around the optimal ratio will sediment quickly such that a maximum in transmittance corresponds to the optimal ratio. Results are shown in Figure 3. It is found that the optimal weight ratio for soy extract/gum arabic is from 1:0.7 to $1: 0.3$ and from $1: 0.3$ to $1: 0.1$ for pea extract/gum arabic. The pea extract requires less gum arabic for complex coacervation because the pea extract has less protein than the soy extract. Furthermore, we noticed that the pea extract/gum arabic complex coacervate near its optimal ratios needed around $3 \mathrm{~h}$ to sediment, while for the soy extract/gum arabic complex coacervate, this only took half an hour, pointing to slower coalescence and smaller droplet size at optimal amounts of gum arabic for the case of the pea extracts.

Complex Formation at Different $\mathrm{pH}$ Values. The condition of electroneutrality and the resulting optimal mass ratio of course sensitively depends on $\mathrm{pH}$, since this sets the charges on the macroions. To investigate $\mathrm{pH}$ dependence, we fix the mass ratio at the optimal value found for $\mathrm{pH} 3$ and explore the $\mathrm{pH}$ dependence at this mass ratio. We find 


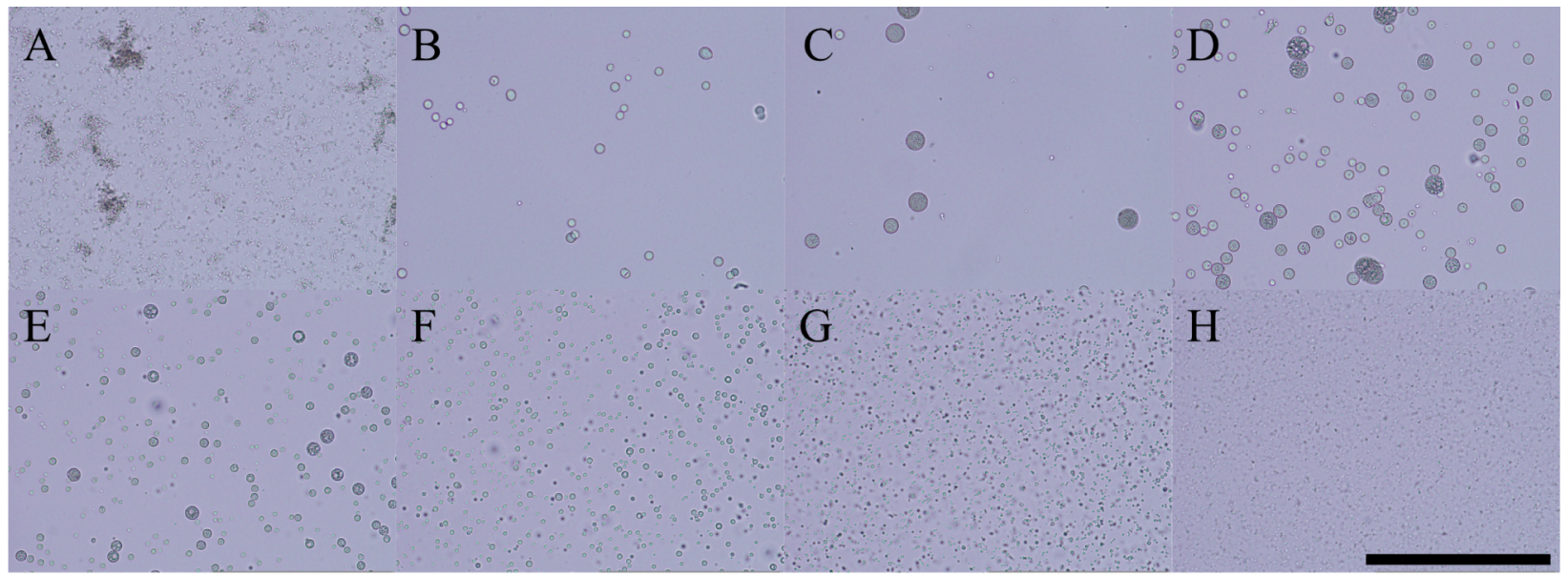

Figure 2. Micrographs of mixtures of soy extract and gum arabic with different polymer ratios at $\mathrm{pH}$. These ratios are soy extract/gum arabic $=$ (A) $1: 0.1$, (B) $1: 0.3$, (C) $1: 0.5$, (D) $1: 0.7$, (E) 1:1, (F) 1:1.5, (G) $1: 2$, and (H) $1: 5$. The scale bar is $200 \mu \mathrm{m}$.

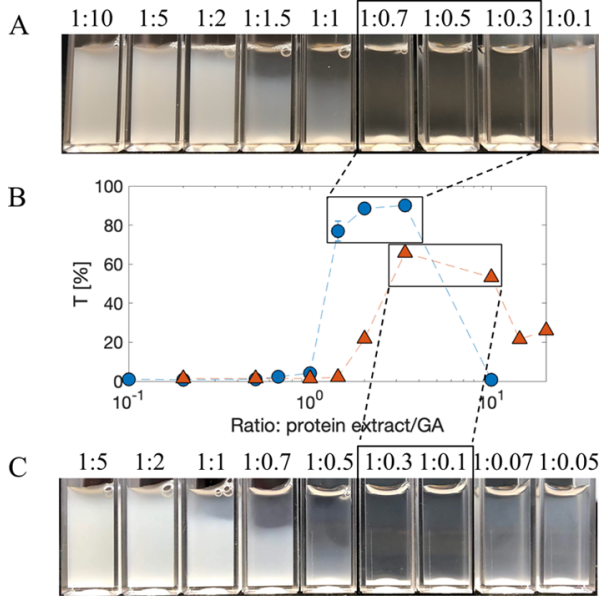

Figure 3. (A) Mixed solutions of soy extract and gum arabic in different ratios (soy extract/gum arabic) at $\mathrm{pH}$ 3. (B) Measured transmittance $(\lambda=500 \mathrm{~nm})$ as a function of polymer ratio. Circles and triangles represent soy and pea mixed solutions, respectively. Error bars show the standard deviation of triplicates, if invisible, error bars are smaller than symbols. The optimal ratios are highlighted in boxes. (C) Mixed solutions of the pea extract and gum arabic at $\mathrm{pH} 3$ with their ratios being indicated in the same manner (pea extract/gum arabic).

distinctly different behaviors for the two types of protein extracts. As shown in Figure 4, for the soy extract/gum arabic coacervate system, spherical coacervate droplets start appearing at $\mathrm{pH} 2.75$. The droplets remain transparent and spherical up to $\mathrm{pH} 3.25$. At $\mathrm{pH}$ values above $\mathrm{pH} 3.5$, we observe solid aggregates coexisting with some (spherical and transparent) coacervate droplets. The coexistence of different types of complexes strongly suggests that in our protein extracts, different protein fractions (with different charge intensities and solubility properties ${ }^{27,41}$ ) may form segregated complexes. In contrast to the soy protein extracts, for the pea extracts, as shown in Figure 5, upon complexation with gum arabic, coacervate droplets start forming from $\mathrm{pH} \mathrm{2.75,} \mathrm{but} \mathrm{this} \mathrm{time,}$ no obvious large aggregates are found until at least $\mathrm{pH} 5$. Rather than being caused by differences in electrostatic interactions, we believe that the difference between the behavior of the two types of extracts is caused by differences in solubility of proteins in the extracts. As we show in Figure $\mathrm{S} 4$, the $\mathrm{pH} 3$ soy protein extracts start showing precipitation when brought to $\mathrm{pH} \mathrm{4,} \mathrm{while} \mathrm{for} \mathrm{the} \mathrm{pea} \mathrm{protein} \mathrm{extracts,} \mathrm{this}$ does not occur until at least $\mathrm{pH} 5$.

As shown in Figure 6A, we have also determined coacervate yields and the total (bio)polymer content of the coacervates as a function of $\mathrm{pH}$. We find that starting from low $\mathrm{pH}$, both increase up to $\mathrm{pH} 3$ and then stay roughly constant. For both the soy and pea protein extracts, the total polymer content in the coacervates reaches a maximum of around $20 \%$, which is similar to values reported for many other coacervate systems consisting of proteins from animal sources ${ }^{42}$ or synthetic

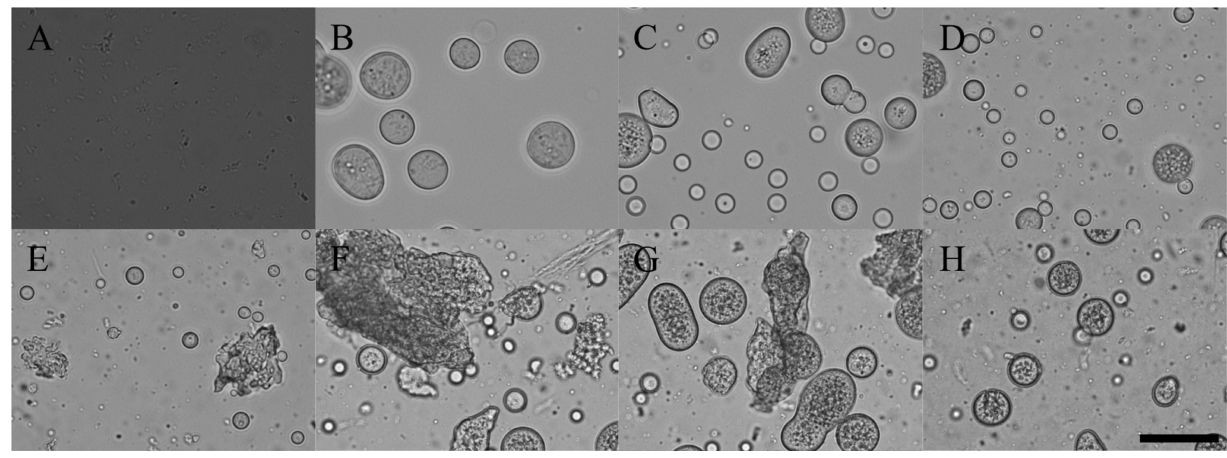

Figure 4. Micrographs of soy extract/gum arabic complex coacervate at different pH values (A) 2.43, (B) 2.75, (C) 3, (D) 3.25, (E) 3.5, (F) 3.75, (G) 4, and (H) 5. The scale bar is $50 \mu \mathrm{m}$. 


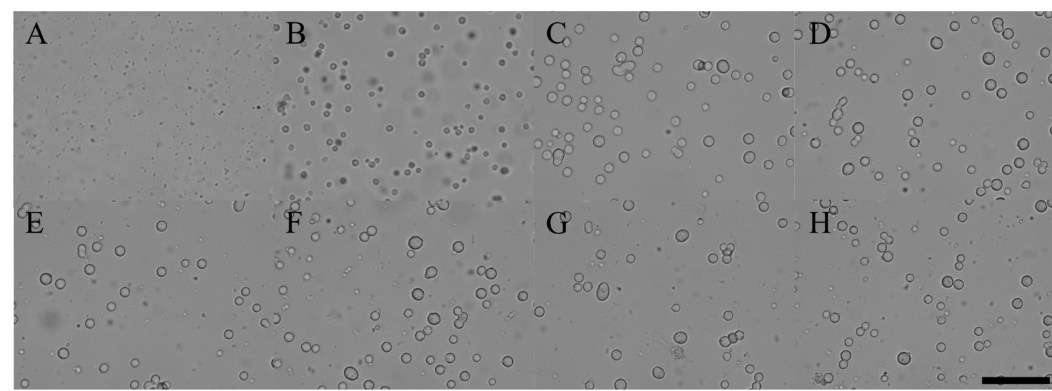

Figure 5. Micrographs of pea extract/gum arabic complex coacervate at different pH values (A) 2.5, (B) 2.75, (C) 3, (D) 3.25, (E) 3.5, (F) 3.75, (G) 4 , and (H) 5. The scale bar is $50 \mu \mathrm{m}$.
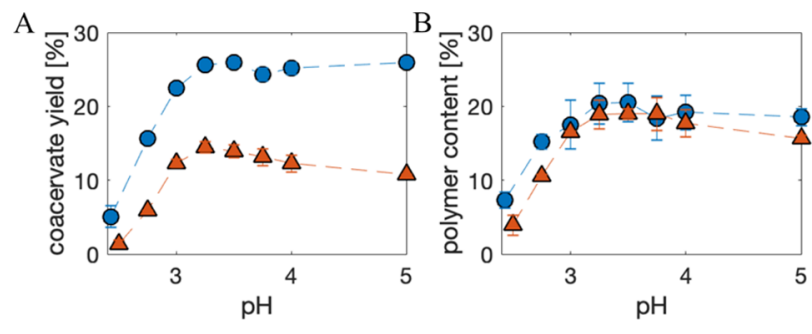

Figure 6. Coacervate yields (A) and polymer contents in coacervates (B) as a function of $\mathrm{pH}$. Coacervate yields are determined by the mass of polymers in coacervates divided by the total polymer mass in solutions. Polymer contents are obtained by the mass of polymers in coacervates divided by the total coacervate mass. Circles and triangles represent soy and pea extract/gum arabic coacervates, respectively. Error bars show the standard deviation of triplicates.

polymers. $^{22}$ The coacervate yield is much higher for coacervates of gum arabic with the soy than with the pea protein extracts (Figure 6A); hence, the coacervates with the pea protein extracts feature significantly more biopolymer dissolved in the continuous phase. Presumably, this reflects both the higher protein solubility and the lower fraction of protein extracted for the case of pea.

Protein Composition. To investigate which protein fractions are extracted and contribute to complex coacervation at the optimal polymer ratios and $\mathrm{pH}$, polyacrylamide gel electrophoresis (SDS-PAGE) was used to study soy and pea extracts, as well as their coacervates with gum arabic (Figure 7). Glycinin and $\beta$-conglycinin are two major components of

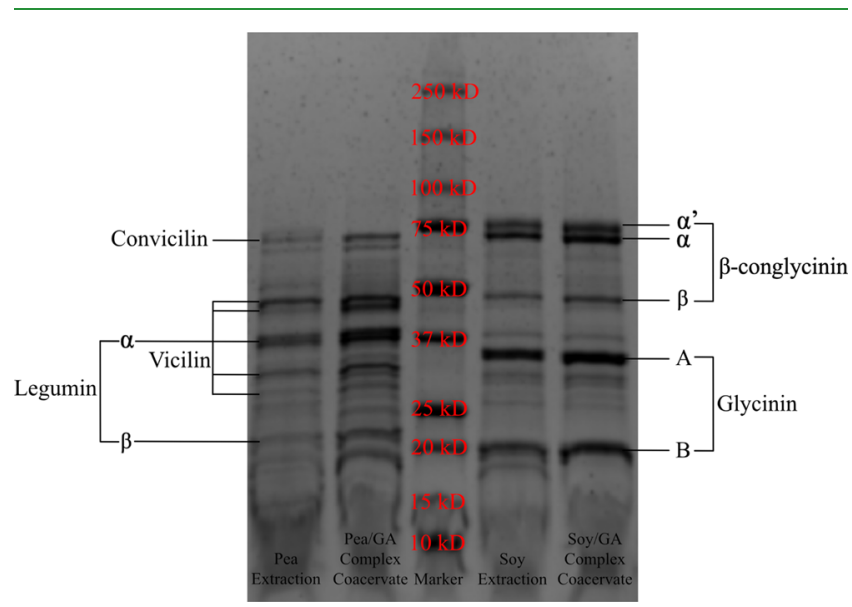

Figure 7. SDS-PAGE of the pea extract, pea extract/gum arabic complex coacervate (left) and the soy extract, soy extract/gum arabic complex coacervate (right). soy globulins, and these two components together take up around $60 \%$ of the total soy protein content. ${ }^{38}$ They are found in both the soy extracts and the coacervates, with no apparent change in their relative abundance. In pea protein fractions, globulins take up $70-80 \%$ of the total protein content. ${ }^{26}$ Globulins in pea consist of three main fractions: legumin, vicilin, and convicilin. All are found in the pea protein extracts and in the coacervates. As is clear from Figure 7, also for pea, the relative abundance of the proteins appears to be essentially the same in the protein extract and in its coacervates. Hence, all major protein fractions from soy and pea flours are successfully extracted and efficiently used in complex coacervation in our process.

Salt and Concentration Dependence of Interfacial Tension. After studying the complex coacervation behavior of the soy and pea extracts with gum arabic, we next focus on the major physical property determining core-shell capsule formation: the extremely low interfacial tensions $\gamma$ of the coacervates with their excess phases which typically leads to full wetting of coacervates at oil-water interfaces. ${ }^{43}$ In addition to viscous forces and external flow, it is this interfacial tension that largely determines the capsule size and morphology. ${ }^{17,44}$ However, because of their extremely low values, measuring $\gamma$ between coacervate phases and their coexisting aqueous phases is difficult.

In recent years, several creative techniques ${ }^{17,20,32-34,45,46}$ have been developed to measure the extremely low $\gamma$ of coacervates. We here use the CP-AFM-based method developed by Sprakel et al., which has also been adopted by other groups. ${ }^{33,34}$ Details of the technique are explained elsewhere, ${ }^{20,32,34}$ but in brief, a coacervate bridge is formed between the colloid probe and substrate by either capillary condensation in the polymer dilute phase or by direct contact with a substrate precoated with coacervates. A schematic is shown in Figure 8. In practice, retraction of the colloid probe increases the surface area of the capillary bridge and leads to an increase in the interfacial energy and a measurable force response, from which the surface tension can be inferred.

So far, this technique has been applied to relatively welldefined model systems. Here, we show that it is also very suitable to precisely measure interfacial tensions in our more complex mixed systems. We follow Sprakel et al. in using capillary condensation as our means of creating the capillary bridges: these form spontaneously when immersing the colloid probe in the excess phase that surrounds the dense coacervate droplets and bringing the colloid probe close to the interface.

First, we perform controls to rule out forces due to mechanisms other than capillary bridge formation, following the same reasoning as Sprakel et al. and Spruijt et al. ${ }^{20,32}$ No 


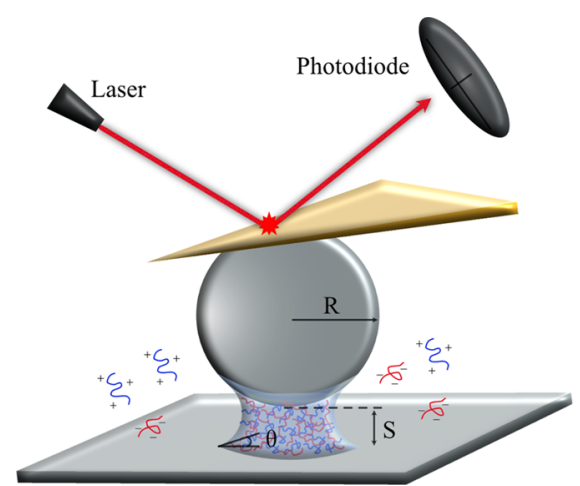

Figure 8. Artistic illustration of the capillary bridge geometry, with the complex coacervate condensed between the sphere and the substrate. Reproduced from ref 20 with permission from The Royal Society of Chemistry.

bridging is found in solutions with either only gum arabic or only protein extract due to the absence of phase separation in those cases. Next, the range of the attraction range found for mixtures of gum arabic and protein extracts $(100 \mathrm{~nm})$ is many times that of interactions such as a depletion interaction. ${ }^{47}$ Similarly, van der Waals attractions are ruled out because no hysteresis is observed in pure water or salt solutions. Hence, we conclude that the long-range attractions we observe in mixtures of gum arabic and extracts of soy and pea proteins can be attributed to the capillary bridge.

Next, we have measured force-distance curves for soy and pea extract/gum arabic coacervates for a wide range of retraction rates (from 0.1 to $5 \mu \mathrm{m} / \mathrm{s}$ ) and four salt concentrations $(0,30,60$, and $90 \mathrm{mM})$. Results for soy extract/gum arabic coacervates are shown in Figure 9. For the
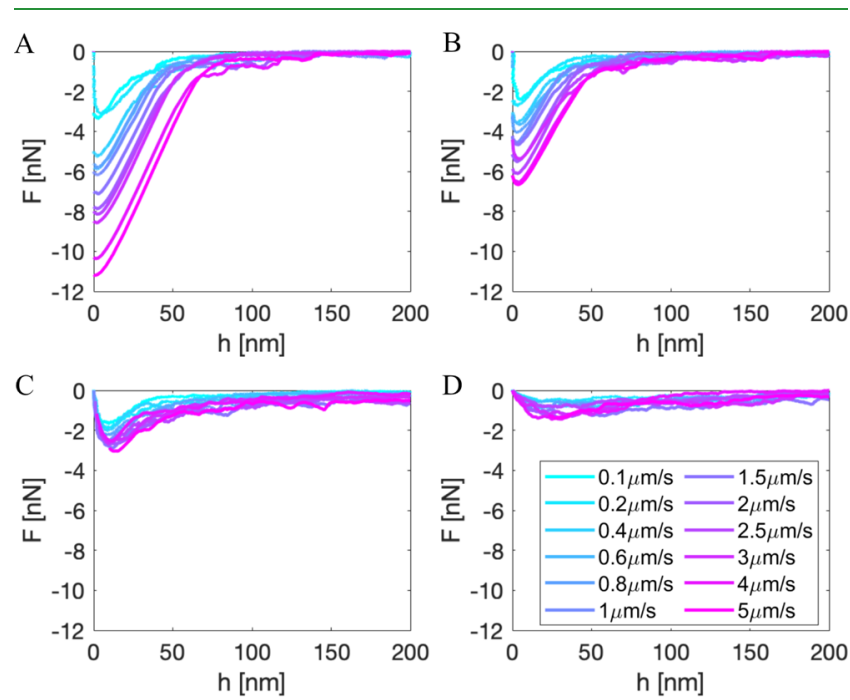

Figure 9. Retraction force-distance curves of soy extract/gum arabic coacervates at different retraction rates (from 0.1 to $5 \mu \mathrm{m} / \mathrm{s}$ ) and different salt concentrations, (A) 0, (B) 30, (C) 60, and (D) $90 \mathrm{mM}$.

equivalent results for pea extract/gum arabic coacervates, see Figures S5 and S6. Two features are very prominent in Figure 9: the magnitude of the force strongly decreases with increasing salt concentrations and the magnitude of the force also increases significantly with increasing retraction rates.

The former behavior is expected, as the salt screens the electrostatic interactions that drive coacervate formation. Too much salt eventually leads to the disappearance of the coacervates and hence to a vanishing surface tension. A rate dependence of the force has been reported before, ${ }^{34,45}$ while in other cases, no dependence on retraction rates was found. It was already pointed out before ${ }^{17}$ that at high retraction rates, the bulk coacervate viscosity will make a rate-dependent contribution to the force response that cannot be neglected. Hence, we have modified the analysis of the force curves to also account for the (rate-dependent) effect of coacervate viscosity on the observed forces.

First, peak forces $F$ are plotted against retraction rates for different salt concentrations (Figure 10A). Two regions can
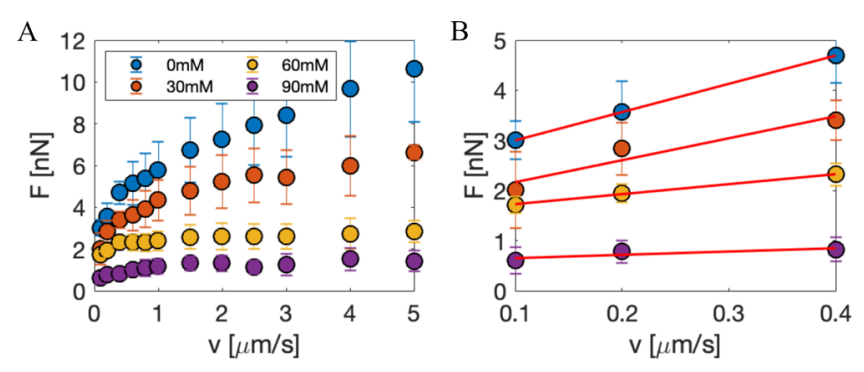

C

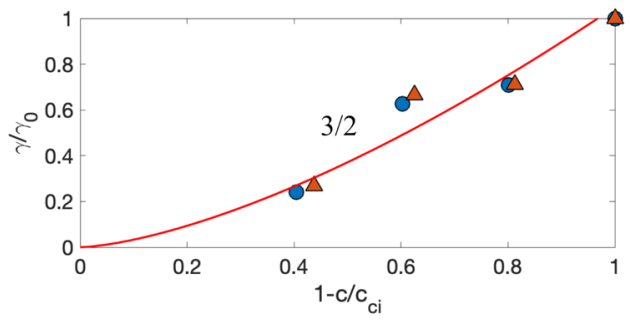

Figure 10. (A) Peak forces as a function of retraction rates for soy extract/gum arabic coacervates at different salt concentrations, error bars show the standard deviation of 20 measurements. (B) Zoom-in figure of panel $\mathrm{A}$ at low retraction rates (from 0.1 to $0.4 \mu \mathrm{m} / \mathrm{s}$ ) with linear fits. (C) Normalized interfacial tensions of soy (circles) and pea (triangles) extract/gum arabic coacervates as a function of the normalized separation from their critical salt concentrations, soy (151 $\mathrm{mM})$ and pea $(160 \mathrm{mM})$. The solid line is a power law fit with an exponent of $3 / 2$ as predicted by Spruijt et al. ${ }^{20}$

clearly be distinguished: at low retraction rates $(<0.4 \mu \mathrm{m} / \mathrm{s}), F$ increases linearly. At high rates $(>0.4 \mu \mathrm{m} / \mathrm{s})$, curves start to level off. We observe that this trend is similar to what is observed for a shear thinning fluid behavior obtained using macroscale rheology, with the slope of the force versus rate curve representing viscosity. Hence, by analogy, we identify the low retraction rate regime as the linear, Newtonian regime.

To eliminate the viscosity effect which depends on retraction rates, we obtain the peak force $F$ for the zero retraction rate using a linear fit (Figure 10B). When the retraction rate is zero, the peak force $F$ solely comes from the interfacial tension $\gamma$. Furthermore, for simplicity, we assume that the peak force $F$ occurs at zero separation $(S=0)$ for all measurements. A wellknown solution ${ }^{33}$ for the sphere-plate geometry is

$$
F=4 \pi \gamma R \cos \theta
$$

where $R$ is the probe radius and $\theta$ is the contact angle between coacervates and the substrate. We assume that the contact angle is small and $\cos \theta \approx 1$, since the coacervates wet both the substrate and probe.

Interfacial tensions $\gamma$ of soy and pea extract/gum arabic coacervates are calculated from eq 1 . We find that the soy and 
pea extract/gum arabic coacervates have, respectively, $\gamma=48.5$ and $32.3 \mu \mathrm{N} / \mathrm{m}$ in the absence of salt. As expected, with increasing salt concentration, the interfacial tensions decrease and eventually vanish (Figure 10C). The salt dependence of model-complex coacervates has previously been explained semiquantitatively using the Voorn-Overbeek model for bulk coacervates and a Flory-Huggins-like expression for the interfacial tension of polymer solutions by Spruijt et al. ${ }^{20}$ (and elaborated by Qin et al. $^{48}$ ). The main prediction is that the interfacial tension should vanish at increasing salt concentrations according to a power law with an exponent $3 / 2$. The critical salt concentrations (soy: $151 \mathrm{mM}$ and pea: $160 \mathrm{mM}$ ) determined via using this scaling exponent are very consistent with observations on bulk coacervate samples, soy and pea extract/gum arabic complex coacervate solutions become transparent above their critical salt concentrations. It is surprising that this model also very nicely captures the salt dependence of the interfacial tension for our multicomponent complex coacervates with crude soy and pea protein extracts.

Heat-Induced Cross-Linking of Coacervates. The ultralow interfacial tensions of the coacervates favor the wetting of the coacervates at the oil-water interface and the formation of a continuous layer. For actual applications of coacervate core-shell particles as microcapsules, usually a curing step is needed in which the coacervate material is solidified. ${ }^{17}$ The solidification is necessary to prevent the microcapsules from agglomerating and to enhance their stability. Many globular proteins exhibit thermal gelation, and in the present case, this can be used as a clean-label strategy for microcapsule curing. We first study the thermal gelation behavior of bulk soy and pea extract/gum arabic coacervates and their mechanical properties by macroscale rheology.

Figure 11A shows a typical measurement of the linear viscous and elastic moduli $G^{\prime \prime}$ and $G^{\prime}$ during heating and subsequent cooling of the protein-polysaccharide complex coacervates. At $20{ }^{\circ} \mathrm{C}$, the complex coacervate remains liquid, with $G^{\prime \prime}$ being higher than $G^{\prime}$. This is in fact a desired property for coacervates to be applied as coatings. At the start of the heating process, both $G^{\prime \prime}$ and $G^{\prime}$ first decrease, further enhancing the spreading of the coacervates at interfaces. At a temperature between 40 and $60{ }^{\circ} \mathrm{C}$, the elastic moduli $G^{\prime}$ finally exceed the viscous moduli $G^{\prime \prime}$, and the coacervates have gelled. Both $G^{\prime}$ and $G^{\prime \prime}$ reach plateau values at $80{ }^{\circ} \mathrm{C}$. After cooling, the elastic modulus $G^{\prime}$ is around $10^{5} \mathrm{~Pa}$, which is 1 order of magnitude larger than the viscous modulus $G^{\prime \prime}$. Hence, we find that heat-induced gelation is a potentially convenient process to cure the coacervates, since this forms strong and irreversible gels.

We have also investigated the influence of $\mathrm{pH}$ on gel strength. Results are shown in Figure 11B. Before heating, the $G^{\prime}$ of pea extract/gum arabic coacervates is slightly higher than that of the soy extract/gum arabic coacervates. When increasing the $\mathrm{pH}$, the elastic moduli $G^{\prime}$ of both coacervates increase and start exceeding the viscous moduli $G^{\prime \prime}$ for $\mathrm{pH}>$ 3.5 for the soy protein extracts and for $\mathrm{pH}>3.25$ for the pea extracts. This is the result of enhanced electrostatic interactions and decreasing solubility of the protein components. This $\mathrm{pH}$ induced liquid-to-solid transition could be used as an initial solidification step for the coacervate phase. After cross-linking, the final $G^{\prime}$ of both coacervates at each $\mathrm{pH}$ is more than 2 orders of magnitude larger than their initial strength. Disulfide bridge formation (between thiol groups of cysteine residues)
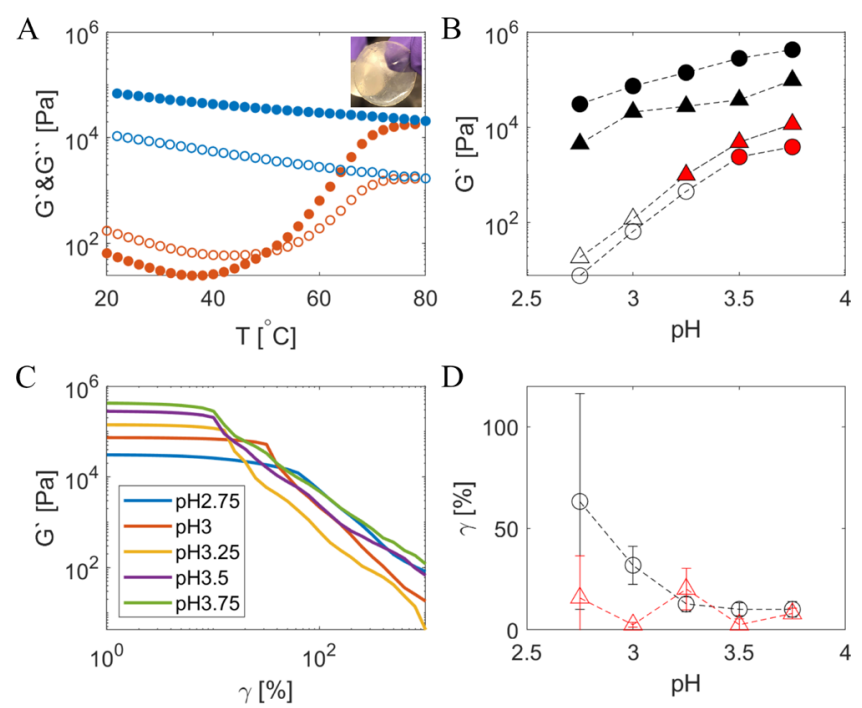

Figure 11. (A) Evolution of the linear viscoelastic properties upon imposing a typical temperature ramp. A representative temperature ramp on soy extract/gum arabic coacervates at $\mathrm{pH}$ 3. Open and solid symbols represent loss modulus $\left(G^{\prime \prime}\right)$ and storage modulus $\left(G^{\prime}\right)$, respectively. Orange and blue colors indicate the heating and cooling process, respectively. The inset shows an example of the cross-linked coacervate probed using a $25 \mathrm{~mm}$ cone-plate geometry on a rheometer. (B) $G^{\prime}$ of soy (circles) and pea (triangles) extract/gum arabic coacervates before (open) and after (filed) cross-linking. The red color indicates that the samples have $G^{\prime}>G^{\prime \prime}$ even before crosslinking. (C) Strain amplitude sweep experiments of soy extract/gum arabic coacervates at different $\mathrm{pH}$ values after cross-linking. (D) Strain-at-break as a function of $\mathrm{pH}$. Soy and pea extract/gum arabic coacervates are represented by circles and triangles, respectively. Error bars are corresponding to the widths of the strain-at-break peaks $\left(\Delta G^{\prime} / \Delta \gamma\right)$ at half prominence.

may play a role in determining the strength of heat-induced gels of globular proteins. We speculate that the higher elastic moduli $G^{\prime}$ of the cured soy extract/gum arabic coacervates as compared to those for pea is due to the higher cysteine content of the soy proteins, as compared to the pea proteins. ${ }^{49}$ Nevertheless, our speculation is not definitive considering the complex nature of the coacervate systems in our work. Alting et al. have shown that strong gels can be formed even in the absence of any disulfide bridges. ${ }^{50}$ Therefore, the exact gelation mechanism still requires further study.

The nonlinear rheology, in particular, the fracture behavior, is also a key property determining the usefulness of these coacervates for core-shell microcapsules. Typical strain sweeps of (heated) soy extract/gum arabic coacervates are shown in Figure 11C. The critical strains for both soy and pea extract/gum arabic coacervates are summarized in Figure 11D. We find that soy extract/gum arabic coacervates have better fracture resistance than pea extract/gum arabic coacervates at $\mathrm{pH} 2.75$ and 3. Their fracture resistance decreases with increasing $\mathrm{pH}$. In contrast, for pea extract/gum arabic coacervates, the critical strains for fracture are relatively $\mathrm{pH}$ independent. This difference may very well be due to the lower solubility of the soy proteins (Figure S4). Indeed, the soy protein precipitates that are formed at higher $\mathrm{pH}$ values might concentrate stresses in the hydrogels that promote fracture.

On balance, we conclude that increasing $\mathrm{pH}$ after coacervate spreading at oil-water interfaces may provide a way to obtain 


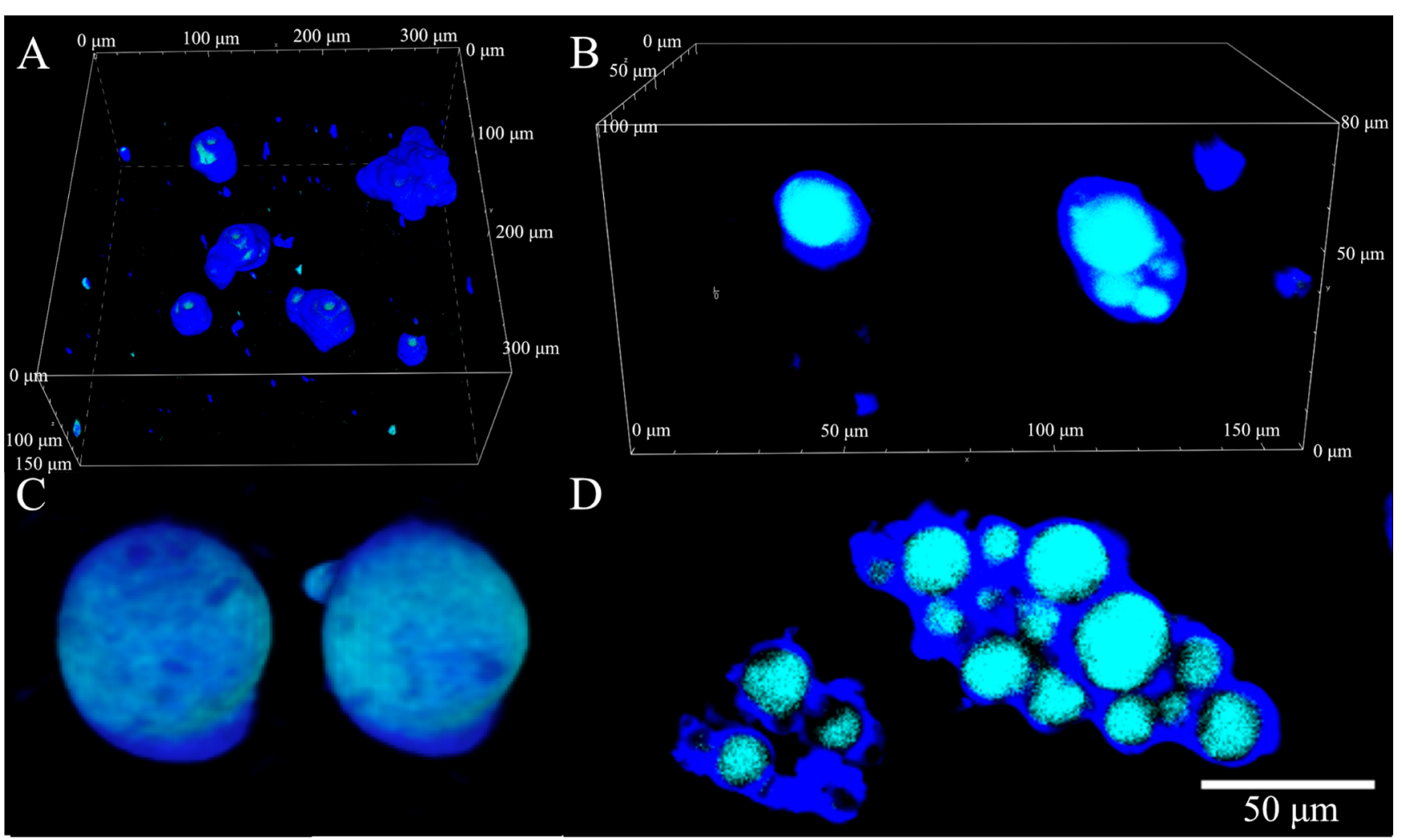

Figure 12. CLSM of the core-shell capsules made from soy extract/gum arabic coacervates. (A) Three-dimensional reconstruction of core-shell capsules formed around $\mathrm{pH} 3$, scales are labeled on the rectangular box. (B) Capsules formed in the same condition as in panel A, and the MaxIP render mode was used to accentuate the internal structure of the capsules. Scales are labeled on the rectangular box. (C) Capsules before crosslinking at $200 \mathrm{mM} \mathrm{NaCl}$. (D) Capsules after cross-linking at $500 \mathrm{mM} \mathrm{NaCl}$. The light blue color corresponds to the oil phase, and dark blue represents the coacervate phase.

yet more rigid capsules after heating, although for the case of soy, this may be at the expense of the fracture strength.

Capsule Morphology and Stability. Finally, we present preliminary results on microcapsules prepared using the soy and pea protein flours. Capsule morphology before heatinduced cross-linking was observed using confocal laser scanning microscopy (CLSM). Figure 12A and B shows three-dimensional reconstructions of oil droplets encapsulated by soy extract/gum arabic coacervates. A thick coacervate layer (a few micrometers) around oil droplets can clearly be recognized (Figure 12A). From Figure 12B, which emphasizes the internal structure of the capsules, it is clear that some capsules can have multiple oil cores. Although not explored here, the capsule size and core density could be further controlled by tuning the coacervate viscosity and flow applied during capsule formation. ${ }^{17,51}$

Salt stability is a crucial parameter for the cured core-shell microcapsules. Before cross-linking (Figure 12C), soy extract/ gum arabic coacervate capsules are dissolved in $200 \mathrm{mM} \mathrm{NaCl}$ after around $3 \mathrm{~h}$, which is above the critical salt concentration determined from CP-AFM measurements. Only a small amount of proteins or gum arabic, which can act as emulsifiers, stay at the oil-water interface. In contrast, capsules crosslinked via heat-induced gelation remain stable at $500 \mathrm{mM}$ $\mathrm{NaCl}$ for at least $3 \mathrm{~h}$ (Figure 12D). Furthermore, the crosslinked capsules also show good stability at neutral $\mathrm{pH}$, for storage times of up to at least several weeks (Figure S7). Very similar results were found for capsules formulated with pea extract/gum arabic coacervates (Figure S8).

\section{CONCLUSIONS}

We have demonstrated a straightforward two-step approach to formulate plant-based complex coacervates, directly using legume flours rather than protein isolates. We find that the soluble proteins can be effectively extracted from legume flours in an acidic environment and spontaneously form complex coacervates in this acidic environment after adding weakly negatively charged polysaccharides such as gum arabic. In line with the sustainable formulation of the coacervates, we demonstrate that simple heating is enough to cure coreshell capsules prepared with these coacervates, and no chemical cross-linking is necessary. In conclusion, we show that the sustainable fabrication of advanced microstructures is possible starting from raw ingredients and that resource intensive purification of plant biopolymers is not a prerequisite for creating such structures.

\section{EXPERIMENTAL SECTION}

Materials. Soybean flour (S9633), Nile blue A perchlorate (370088), oil red O (O0625), gum arabic (51198), chitosan (448869), and (R)-(+)-limonene $(97 \%, 183164)$ were bought from Sigma-Aldrich. Pea flour (yellow pea) and a medium-chain triglyceride (NEOBEE M-5) were gifts from AM Nutrition and Stepan Company, respectively. In the comparison test, the soy protein isolate (SUPRO) was bought from Solae and the pea protein isolate (NUTRALYS F85) was bought from Roquette. Sodium metabisulfite $(97 \%+)$ was bought from Acros Organics. $\mathrm{HCl}$ and $\mathrm{NaOH}(1$ and 0.1 $\mathrm{N})$ solutions purchased from Merck were used to control $\mathrm{pH}$. Milli-Q water was used in all experiments. 
Protein Extraction and Yield Determination. Typically, a mixture of $10 \% \mathrm{w} / \mathrm{w}$ soy or pea flour with sodium metabisulfite (15 $\mathrm{mM})$ (prevent disulfide aggregates) ${ }^{27}$ was prepared in demineralized water $(100 \mathrm{~mL}) \cdot \mathrm{pH}$ was adjusted to 2.7 with $1 \mathrm{M} \mathrm{HCl}$, and the mixture was then vigorously stirred for $1 \mathrm{~h}$. $\mathrm{pH}$ was controlled between 2.7 and 2.9 during this process. The resulting mixture was centrifuged at $10,000 \mathrm{~g}$ for $30 \mathrm{~min}$ and the supernatant was collected, which contains soluble components (mostly protein and carbohydrate) from the corresponding flour. The supernatant was then freezedried for storage and later use. The nitrogen content of flours and extracts was measured by the Dumas method. A general nitrogen-toprotein conversion factor of 6.25 was used to calculate the protein content for both soy and pea.

Optimal Ratio Determination. The optimal ratios for soy and pea extract/gum arabic complex coacervates at $\mathrm{pH} 3$ were determined by sweeping a wide range of polymer ratios. Specifically, for soy extract/gum arabic complex coacervates, a stock solution of soy extracts $(\mathrm{pH} \mathrm{3}, 0.005 \mathrm{~g} / \mathrm{mL})$ was prepared. We mixed the soy stock solution $(10 \mathrm{~mL})$ with gum arabic solutions $(10 \mathrm{~mL}, \mathrm{pH} 3)$ with different concentrations $(0.0005,0.0015,0.0025,0.0035,0.005$, $0.0075,0.01,0.025$, and $0.05 \mathrm{~g} / \mathrm{mL})$. The final concentration of soy extracts was kept constant for all samples. The mixed solutions were also controlled at $\mathrm{pH}$ 3. All samples were observed in both micro- and macroscopic ways. A bright-field light microscope was used to check the mixed solutions. We transferred each sample $(2 \mathrm{~mL})$ into cuvette cells and left them to stand still for around $30 \mathrm{~min}$. After that, the turbidity of the solutions was determined by the transmittance of a visible light $(\lambda=500 \mathrm{~nm})$ measured using a spectrophotometer (evolution 220 Thermo Scientific). For pea extract/gum arabic complex coacervates, mixed solutions were prepared in the same manner but in different concentrations. We mixed the pea extract stock solution $(10 \mathrm{~mL}, \mathrm{pH} 3,0.02 \mathrm{~g} / \mathrm{mL})$ with gum arabic solutions $(10 \mathrm{~mL}, \mathrm{pH} 3)$ with different concentrations $(0.001,0.0014,0.002$, $0.006,0.01,0.014,0.02,0.04$, and $0.1 \mathrm{~g} / \mathrm{mL}$ ). Moreover, longer waiting time for transmittance measurements was required for pea samples, which was around $3 \mathrm{~h}$.

Optimal pH Determination. The optimal pH for soy and pea extracts forming complex coacervates with gum arabic was determined at the following fixed polymer ratios: soy extract/gum arabic $=1: 0.7$ and pea extract $/$ gum arabic $=1: 0.3$. Their total polymer concentrations were kept constant $(11.9 \mathrm{mg} / \mathrm{mL})$. Stock solutions of soy extract, pea extract, and gum arabic were prepared at $\mathrm{pH}$ between 2.4 and 2.5. After mixing, solutions were in these two fixed ratios, we slowly increased the $\mathrm{pH}$ from 2.5 to $2.75,3,3.25,3.5,3.75$, 4 , and 5 . At each $\mathrm{pH}$, microscopic images were taken. Furthermore, a total volume of $30 \mathrm{~mL}$ solutions for each $\mathrm{pH}$ were transferred to three centrifuge tubes with an equal volume. All samples were centrifuged at $4500 \mathrm{rpm}$ at room temperature for $30 \mathrm{~min}$. The coacervate phase was freeze-dried to determine the coacervate yield and polymer content. Finally, the solubility of individual soy and pea extracts $(1 \mathrm{mg} / \mathrm{mL})$ at different $\mathrm{pH}$ values $(3,3.5,4$, and 5$)$ was studied.

SDS-PAGE. The protein composition of soy and pea extracts and their complex coacervates with gum arabic was studied by SDSPAGE. Gel electrophoresis was conducted using commercial SDS/ polyacrylamide gels (4-20\% Mini-PROTEAN TGX precast gels, BioRad). Reference protein marker was purchased from BioRad. GelCode Blue Safe Protein Stain (Thermo Scientific) was used for staining.

CP-AFM and Salt Dependence of Interfacial Tensions. Force measurements were performed on an atomic force microscope (ForceRobot 300, JPK). An AFM cantilever with a spherical silica particle $(d=8 \mu \mathrm{m})$ was sealed in a liquid chamber by a rubber ring on a silicon wafer as the substrate. Both the AFM probe and substrate were cleaned via plasma and rinsed with water prior to measurements. Complex coacervates of soy and pea extracts with gum arabic were prepared at $\mathrm{pH} 3$ and with fixed polymer ratios (soy extract/gum arabic $=1: 0.7$ and pea extract $/$ gum arabic $=1: 0.3)$. The total polymer concentration was kept constant and extremely low $(1.1875 \mathrm{mg} / \mathrm{mL})$. Different salt concentrations $(0,30,60$, and $90 \mathrm{mM})$ were tested for both coacervates. The chamber was filled with freshly prepared complex coacervate solutions and incubated about half an hour to reach equilibrium. Two surfaces (substrate and probe) were brought into direct contact $(S=0)$ as the reference height, which was used to determine the absolute separation. The probe and substrate were kept in contact for $10 \mathrm{~s}$ for capillary bridge nucleation and growth. The probe was retracted at different velocities ranging from 0.1 to $5 \mu \mathrm{m} / \mathrm{s}$, and force distance curves were recorded. We conducted 20 measurements for each retraction velocity. The vertical tip position was calibrated from cantilever bending using the JPK data processing software. The cantilever deflection was converted to force using Hooke's law, $F=k \Delta x . k$ is the spring constant of the cantilever, which was calibrated by a contact-based method in air. In this study, the spring constant was $0.203 \mathrm{~N} / \mathrm{m}$.

Coacervate Cross-Linking and Rheology. Heat-induced crosslinking of soy and pea extract/gum arabic coacervates and their mechanical properties were studied by rheology. Complex coacervates of soy and pea extracts with gum arabic were prepared at their optimal ratios and various $\mathrm{pH}$ values (from 2.75 to 3.75). Rheological measurements were performed on an Anton Paar 501 rheometer equipped with a $25 \mathrm{~mm}$ cone-plate geometry and a Peltier temperature control unit. A solvent trap with tetradecane was used to prevent water evaporation. The continuous coacervate phase was obtained by centrifugation ( $4500 \mathrm{rpm}, 30 \mathrm{~min}$ ) and subsequently loaded on the rheometer. First, a temperature ramp was conducted to induce gelation, the temperature was increased from 20 to $80^{\circ} \mathrm{C}$ in 1 h, kept at $80{ }^{\circ} \mathrm{C}$ for $5 \mathrm{~min}$, and finally decreased to $20{ }^{\circ} \mathrm{C}$ with the same rate. $G^{\prime}$ and $G^{\prime \prime}$ were monitored at $0.5 \%$ stain and $6.28 \mathrm{rad} / \mathrm{s}$. Then, the fracture resistance was tested via an amplitude sweep until $1000 \%$ strain at $6.28 \mathrm{rad} / \mathrm{s}$ and $20{ }^{\circ} \mathrm{C}$.

Capsule Preparation and CLSM. First, stock solutions of soy and pea extracts were prepared at $\mathrm{pH} 2.6$, and gum arabic stock solutions were prepared at $\mathrm{pH}$ 2.9. Then, we prepared mixed solutions $(40 \mathrm{~mL})$ with fixed polymer ratios (soy extract/gum arabic $=1: 0.7$ and pea extract/gum arabic $=1: 0.3$ ) and a constant total polymer concentration $(11.9 \mathrm{mg} / \mathrm{mL})$. We added mixed oil $(0.5 \mathrm{~mL}, 80 \mathrm{vol} \%$ NEOBEE M5 + 20 vol \% limonene) to the mixed solutions followed by an emulsification step using ULTRA-TURRAX. $\mathrm{pH}$ of the mixed solutions was slowly increased to around 3 to induce complex coacervation and form capsules. The obtained capsules were further cross-linked by heating in a preheated water bath at $80{ }^{\circ} \mathrm{C}$ for $1 \mathrm{~h}$. Capsule stability was tested by adding $\mathrm{NaCl}$ and adjusting to neutral $\mathrm{pH}$. CLSM was conducted on an inverted microscope system Eclipse $\mathrm{Ti}_{2}$ from Nikon. Two excitation wavelengths, 488 and $640 \mathrm{~nm}$, were used to probe the local environments of Nile Blue-dyed oil phase and proteins, respectively.

\section{ASSOCIATED CONTENT}

\section{Supporting Information}

The Supporting Information is available free of charge at https://pubs.acs.org/doi/10.1021/acsami.1c06896.

Photographs of aqueous solutions of commercial plant protein isolates; micrographs of mixtures of commercial plant protein isolates with polysaccharides; micrographs of pea extracts and gum arabic with different polymer ratios at $\mathrm{pH} 3$; micrographs of soy and pea extracts at different $\mathrm{pH}$ values; retraction force-distance curves of pea extract/gum arabic complex coacervates; peak force as a function of retraction rates for pea extract/gum arabic coacervates; CLSM of soy extract/gum arabic complex coacervate core-shell capsules near $\mathrm{pH} 7$; and CLSM of core-shell capsules made from pea extract/ gum arabic complex coacervates (PDF)

\section{AUTHOR INFORMATION}

\section{Corresponding Author}

Renko de Vries - Physical Chemistry and Soft Matter, Wageningen University and Research, 6708 WE Wageningen, 
The Netherlands; 이이이.org/0000-0001-8664-3135; Email: renko.devries@wur.nl

\section{Authors}

Xiufeng Li - Physical Chemistry and Soft Matter, Wageningen University and Research, 6708 WE Wageningen, The Netherlands; (1) orcid.org/0000-0002-7615-4693

Jasper van der Gucht - Physical Chemistry and Soft Matter, Wageningen University and Research, 6708 WE Wageningen, The Netherlands; ㅇo이.org/0000-0001-5525-8322

Philipp Erni - Corporate Research Division, Materials Science Department, Firmenich SA, 1217 Geneva, Switzerland; (1) orcid.org/0000-0002-4241-0898

Complete contact information is available at: https://pubs.acs.org/10.1021/acsami.1c06896

\section{Notes}

The authors declare no competing financial interest.

\section{ACKNOWLEDGMENTS}

X.L., J.v.d.G., and R.d.V acknowledge financial support from Firmenich SA (grant no: OVK 16/001/20170605).

\section{REFERENCES}

(1) Mohanty, A. K.; Misra, M.; Drzal, L. T. Sustainable biocomposites from renewable resources: opportunities and challenges in the green materials world. J. Polym. Environ. 2002, 10, 19-26.

(2) Klemm, D.; Kramer, F.; Moritz, S.; Lindström, T.; Ankerfors, M.; Gray, D.; Dorris, A. Nanocelluloses: a new family of nature-based materials. Angew. Chem., Int. Ed. 2011, 50, 5438-5466.

(3) Mooney, B. P. The second green revolution? Production of plant-based biodegradable plastics. Biochem. J. 2009, 418, 219-232.

(4) Ramesh, M.; Palanikumar, K.; Reddy, K. H. Plant fibre based bio-composites: Sustainable and renewable green materials. Renew. Sustain. Energy Rev. 2017, 79, 558-584.

(5) Gallezot, P. Conversion of biomass to selected chemical products. Chem. Soc. Rev. 2012, 41, 1538-1558.

(6) Lin, Y.; Tanaka, S. Ethanol fermentation from biomass resources: current state and prospects. Appl. Microbiol. Biotechnol. 2006, 69, 627-642.

(7) Iravani, S.; Varma, R. S. Plants and plant-based polymers as scaffolds for tissue engineering. Green Chem. 2019, 21, 4839-4867.

(8) Zhang, Y.; Cui, L.; Che, X.; Zhang, H.; Shi, N.; Li, C.; Chen, Y.; Kong, W. Zein-based films and their usage for controlled delivery: Origin, classes and current landscape. J. Contr. Release 2015, 206, 206-219.

(9) Li, X.; de Vries, R. Interfacial stabilization using complexes of plant proteins and polysaccharides. Curr. Opin. Food Sci. 2018, 21, $51-56$.

(10) Tanger, C.; Engel, J.; Kulozik, U. Influence of extraction conditions on the conformational alteration of pea protein extracted from pea flour. Food Hydrocolloids 2020, 107, 105949.

(11) Xing, Q.; Kyriakopoulou, K.; de Wit, M.; Boom, R. M.; Schutyser, M. A. I. Effect of tube wall material on electrostatic separation of plant raw-materials. J. Food Process. Eng. 2021, 44, No. e13575.

(12) Kornet, R.; Veenemans, J.; Venema, P.; van der Goot, A. J.; Meinders, M.; Sagis, L.; van der Linden, E. Less is more: Limited fractionation yields stronger gels for pea proteins. Food Hydrocolloids 2021, 112, 106285.

(13) Sridharan, S.; Meinders, M. B. J.; Bitter, J. H.; Nikiforidis, C. V. Pea flour as stabilizer of oil-in-water emulsions: Protein purification unnecessary. Food Hydrocolloids 2020, 101, 105533.

(14) Liao, W.-C.; Sohn, Y. S.; Riutin, M.; Cecconello, A.; Parak, W. J.; Nechushtai, R.; Willner, I. The Application of Stimuli-Responsive VEGF- and ATP-Aptamer-Based Microcapsules for the Controlled
Release of an Anticancer Drug, and the Selective Targeted Cytotoxicity toward Cancer Cells. Adv. Funct. Mater. 2016, 26, $4262-4273$.

(15) de Souza, H. J. B.; Fernandes, R. V. d. B.; Borges, S. V.; Felix, P. H. C.; Viana, L. C.; Lago, A. M. T.; Botrel, D. A. Utility of blended polymeric formulations containing cellulose nanofibrils for encapsulation and controlled release of sweet orange essential oil. Food Bioprocess Technol. 2018, 11, 1188-1198.

(16) Lamprecht, A.; Schäfer, U.; Lehr, C.-M. Influences of process parameters on preparation of microparticle used as a carrier system for $\mathrm{O}$ - 3 unsaturated fatty acid ethyl esters used in supplementary nutrition. J. Microencapsul. 2001, 18, 347-357.

(17) Dardelle, G.; Erni, P. Three-phase interactions and interfacial transport phenomena in coacervate/oil/water systems. Adv. Colloid Interface Sci. 2014, 206, 79-91.

(18) De Jong, H. G. B. Die Koazervation und ihre Bedeutung für die Biologie. Protoplasma 1932, 15, 110-173.

(19) De Kruif, C. G.; Weinbreck, F.; de Vries, R. Complex coacervation of proteins and anionic polysaccharides. Curr. Opin. Colloid Interface Sci. 2004, 9, 340-349.

(20) Spruijt, E.; Sprakel, J.; Cohen Stuart, M. A.; van der Gucht, J. Interfacial tension between a complex coacervate phase and its coexisting aqueous phase. Soft Matter 2010, 6, 172-178.

(21) Dardelle, G.; Jacquemond, M.; Erni, P. Delivery Systems for Low Molecular Weight Payloads: Core/Shell Capsules with Composite Coacervate/Polyurea Membranes. Adv. Mater. 2017, 29, 1606099.

(22) Dompé, M.; Cedano-Serrano, F. J.; Vahdati, M.; Westerveld, L.; Hourdet, D.; Creton, C.; Gucht, J.; Kodger, T.; Kamperman, M. Underwater Adhesion of Multiresponsive Complex Coacervates. Adv. Mater. Interfaces 2020, 7, 1901785.

(23) Cao, Y.; Mezzenga, R. Design principles of food gels. Nat. Food 2020, 1, 106-118.

(24) Warnakulasuriya, S. N.; Nickerson, M. T. Review on plant protein-polysaccharide complex coacervation, and the functionality and applicability of formed complexes. J. Sci. Food Agric. 2018, 98, 5559-5571.

(25) Nesterenko, A.; Alric, I.; Silvestre, F.; Durrieu, V. Vegetable proteins in microencapsulation: A review of recent interventions and their effectiveness. Ind. Crop. Prod. 2013, 42, 469-479.

(26) Lam, A. C. Y.; Can Karaca, A.; Tyler, R. T.; Nickerson, M. T. Pea protein isolates: Structure, extraction, and functionality. Food Rev. Int. 2018, 34, 126-147.

(27) Van Megen, W. H. Solubility behavior of soybean globulins as a function of $\mathrm{pH}$ and ionic strength. J. Agric. Food Chem. 1974, 22, 126-129.

(28) Ducel, V.; Richard, J.; Saulnier, P.; Popineau, Y.; Boury, F. Evidence and characterization of complex coacervates containing plant proteins: application to the microencapsulation of oil droplets. Colloids Surf., A 2004, 232, 239-247.

(29) Liu, S.; Cao, Y.-L.; Ghosh, S.; Rousseau, D.; Low, N. H.; Nickerson, M. T. Intermolecular interactions during complex coacervation of pea protein isolate and gum Arabic. J. Agric. Food Chem. 2010, 58, 552-556.

(30) Liu, S.; Low, N. H.; Nickerson, M. T. Effect of pH, Salt, and Biopolymer Ratio on the Formation of Pea Protein Isolate-Gum Arabic Complexes. J. Agric. Food Chem. 2009, 57, 1521-1526.

(31) Renard, D.; Lavenant-Gourgeon, L.; Ralet, M.-C.; Sanchez, C. AcaciasenegalGum: Continuum of Molecular Species Differing by Their Protein to Sugar Ratio, Molecular Weight, and Charges. Biomacromolecules 2006, 7, 2637-2649.

(32) Sprakel, J.; Besseling, N. A. M.; Leermakers, F. A. M.; Cohen Stuart, M. A. Equilibrium capillary forces with atomic force microscopy. Phys. Rev. Lett. 2007, 99, 104504.

(33) Lim, S.; Moon, D.; Kim, H. J.; Seo, J. H.; Kang, I. S.; Cha, H. J. Interfacial tension of complex coacervated mussel adhesive protein according to the Hofmeister series. Langmuir 2014, 30, 1108-1115. 
(34) Priftis, D.; Farina, R.; Tirrell, M. Interfacial energy of polypeptide complex coacervates measured via capillary adhesion. Langmuir 2012, 28, 8721-8729.

(35) Comert, F.; Dubin, P. L. Liquid-liquid and liquid-solid phase separation in protein-polyelectrolyte systems. Adv. Colloid Interface Sci. 2017, 239, 213-217.

(36) Wu, Q.-X.; Lin, D.-Q.; Yao, S.-J. Design of chitosan and its water soluble derivatives-based drug carriers with polyelectrolyte complexes. Mar. Drugs 2014, 12, 6236-6253.

(37) De Vries, R.; Weinbreck, F.; De Kruif, C. G. Theory of polyelectrolyte adsorption on heterogeneously charged surfaces applied to soluble protein-polyelectrolyte complexes. J. Chem. Phys. 2003, 118, 4649-4659.

(38) Lui, D. Y. M.; White, E. T.; Litster, J. D. Dissolution behavior of soy proteins and effect of initial concentration. J. Agric. Food Chem. 2007, 55, 2467-2473.

(39) Swanson, B. G. Pea and lentil protein extraction and functionality. J. Am. Oil Chem. Soc. 1990, 67, 276-280.

(40) Dubin, P.; Stewart, R. J. Complex coacervation. Soft Matter 2018, 14, 329-330.

(41) Bogracheva, T. Y.; Bespalova, N. Y.; Leont'ev, A. Isolation of $11 S$ and $7 \mathrm{~S}$ globulins from seeds of glycine max. Appl. Biochem. Microbiol. 1996, 32, 429-433.

(42) Weinbreck, F.; Wientjes, R. H. W.; Nieuwenhuijse, H.; Robijn, G. W.; de Kruif, C. G. Rheological properties of whey protein/gum arabic coacervates. J. Rheol. 2004, 48, 1215-1228.

(43) Li, X.; Erni, P.; Van Der Gucht, J.; De Vries, R. Encapsulation Using Plant Proteins: Thermodynamics and Kinetics of Wetting for Simple Zein Coacervates. ACS Appl. Mater. Interfaces 2020, 12, 15802-15809.

(44) Torza, S.; Mason, S. G. Three-phase interactions in shear and electrical fields. J. Colloid Interface Sci. 1970, 33, 67-83.

(45) Ali, S.; Prabhu, V. M. Characterization of the Ultralow Interfacial Tension in Liquid-Liquid Phase Separated Polyelectrolyte Complex Coacervates by the Deformed Drop Retraction Method. Macromolecules 2019, 52, 7495-7502.

(46) Jawerth, L. M.; Ijavi, M.; Ruer, M.; Saha, S.; Jahnel, M.; Hyman, A. A.; Jülicher, F.; Fischer-Friedrich, E. Salt-dependent rheology and surface tension of protein condensates using optical traps. Phys. Rev. Lett. 2018, 121, 258101.

(47) Knoben, W.; Besseling, N. A. M.; Cohen Stuart, M. A. Longrange depletion forces induced by associating small molecules. Phys. Rev. Lett. 2006, 97, 068301.

(48) Qin, J.; Priftis, D.; Farina, R.; Perry, S. L.; Leon, L.; Whitmer, J.; Hoffmann, K.; Tirrell, M.; De Pablo, J. J. Interfacial tension of polyelectrolyte complex coacervate phases. ACS Macro Lett. 2014, 3, 565-568.

(49) Claessens, M.; Calame, W.; Siemensma, A. D.; van Baak, M. A.; Saris, W. H. M. The effect of different protein hydrolysate/ carbohydrate mixtures on postprandial glucagon and insulin responses in healthy subjects. Eur. J. Clin. Nutr. 2009, 63, 48-56.

(50) Alting, A. C.; de Jongh, H. H. J.; Visschers, R. W.; Simons, J.-W. F. A. Physical and chemical interactions in cold gelation of food proteins. J. Agric. Food Chem. 2002, 50, 4682-4689.

(51) Lemetter, C. Y. G.; Meeuse, F. M.; Zuidam, N. J. Control of the morphology and the size of complex coacervate microcapsules during scale-up. AIChE J. 2009, 55, 1487-1496. 